\title{
CONTRIBUIÇÃO DA EDUCAÇÃO FÍSICA PARA O ENSINO MÉDIO: estudo a partir da prática docente de professores de Institutos Federais
}

\author{
Andreia Cristina Metzner \\ Heidi Jancer Ferreira ${ }^{2}$ \\ Hudson Fabricius Peres Nunes ${ }^{3}$ \\ Marcos Roberto $\mathrm{SO}^{4}$ \\ Alexandre Janotta Drigo 5
}

\section{RESUMO}

O objetivo do artigo foi identificar e analisar elementos que contribuem para a consolidação da Educação Física no ensino médio integrado ao ensino técnico a partir de diários de aulas e registros de atividades coordenadas por professores de Institutos Federais, durante um ano letivo. Os dados foram tratados pela análise temática. Foram identificadas quatro unidades temáticas determinantes para a valorização da Educação Física nos Institutos Federais: caracterização da disciplina; perfil profissional dos docentes; ações pedagógicas no ensino de Educação Física; e ações de extensão, pesquisa e atividades extracurriculares. Os resultados indicam que os Institutos Federais oferecem condições satisfatórias para o trabalho docente, possibilitando o enraizamento da Educação Física no currículo a partir de bases teóricas e práticas sistematizadas.

Palavras-chave: Currículo. Ensino. Ações Pedagógicas.

1 Doutoranda em Ciências da Motricidade. Professora do Centro Universitário UNIFAFIBE. Bebedouro/São Paulo, Brasil. E-mail: acmetzner@hotmail.com

2 Doutoranda em Ciências da Motricidade. Professora do Instituto Federal do Sul de Minas (IFSULMINAS), Campus Poços de Caldas. Poços de Caldas/Minas Gerais, Brasil. E-mail: heidi.ferreira@ifsuldeminas.edu.br

3 Mestre em Ciências da Motricidade. Professor do Instituto Federal de São Paulo (IFSP), Campus de Votuporanga. Votuporanga/São Paulo, Brasil. E-mail: hudsonfpnunes@hotmail.com

4 Mestre em Educação. Professor do Instituto Federal do Sul de Minas (IFSULMINAS), Campus Pouso Alegre. Pouso Alegre/Minas Gerais, Brasil. E-mail: marcos.so@ifsuldeminas.edu.br

5 Doutor em Educação Física. Professor da Universidade Estadual Paulista (UNESP), Campus Rio Claro. Rio Claro/ São Paulo, Brasil. E-mail: alexandredrigo@hotmail.com 
CONTRIBUTION OF PHYSICAL EDUCATION TO HIGH SCHOOL: a study based on the teaching practice of teachers of the Federal Institutes

\begin{abstract}
The aim of this article was to identify and analyze elements that contribute to the consolidation of Physical Education in high school integrated to technical education from diaries of classes and records of activities coordinated by teachers from federal institutes during a school year. Data were processed by thematic analysis. Four themes were identified as decisive for the appreciation of Physical Education at federal institutes: features of the discipline; professional profile of the teachers; pedagogical actions in teaching; research and extracurricular activities. Results indicate that the federal institutes offer good conditions for teaching, allowing the setting of Physical Education in the curriculum based on theoretical bases and organized practices.
\end{abstract}

Keywords: Curriculum. Teaching. Pedagogical Actions.

\title{
CONTRIBUCIÓN DE LA EDUCACIÓN FÍSICA PARA LA ESCUELA SECUNDARIA: un estudio de la práctica de los profesores de enseñanza Federales Institutos
}

\section{RESUMEN}

El objetivo del estudio fue identificar y analizar los elementos que contribuyen a la consolidación de la educación física en la escuela secundaria integrada en la educación técnica a partir de los registros de clases y actividades coordinadas por profesores de instituciones federales, durante un año escolar. Los datos fueron procesados por análisis de temas. Cuatro temas fueron identificados como importantes para la valoración de la educación física en los institutos federales: caracterización de la disciplina; el perfil profesional de los docentes; acciones pedagógicas en la enseñanza de la educación física; y los programas de extensión, investigación y actividades extracurriculares. Los resultados indican que los institutos federales ofrecen condiciones satisfactorias para la enseñanza, permitiendo la consolidación de la educación física en el currículo basada en teorías y prácticas sistemáticas.

Palabras claves: Plan de Estudios. Enseñanza. Acciones Pedagógicas. 


\section{INTRODUÇÃO}

A Educação Física surgiu pela primeira vez no currículo escolar por meio da promulgação da Lei de Diretrizes e Bases da Educação Nacional (LDBEN) de 1961. Nessa época, a Educação Física foi considerada obrigatória enquanto prática em todos os níveis de escolarização (BRASIL, 1961).

Em 1996, a lei n. ${ }^{\circ} 9.394$ alterou essa configuração da Educação Física como prática, tornando-a um componente curricular ao apresentar, no parágrafo $3^{\circ}$ do artigo 26 , o seguinte texto: "A educação física, integrada à proposta pedagógica da escola, é componente curricular da Educação Básica, ajustando-se às faixas etárias e às condições da população escolar, sendo facultativa nos cursos noturnos" (BRASIL, 1996, p.10). Contudo, conforme Vago (1999) destaca, essa lei não definiu critérios para a organização do ensino, o que possibilitou o surgimento de diferentes maneiras de incluir a disciplina na prática escolar, até mesmo formas orientadas por interesses econômicos que se preocuparam apenas em cumprir o mínimo estabelecido em lei.

Somente por meio da lei n. ${ }^{\circ}$ 10.328/01 a Educação Física adquiriu o status de componente curricular obrigatório da Educação Básica, passando a ser equiparada às demais disciplinas obrigatórias. Uma nova alteração foi feita pela lei n. ${ }^{0} 10.793 / 03$, permitindo a prática facultativa da Educação Física em casos específicos.

Para Bracht e Almeida (2003), a questão da legitimidade da Educação Física não será resolvida apenas por meio de dispositivos legais. Ela precisa obter a sua legitimidade no campo pedagógico, enquanto prática e disciplina acadêmica.

A Educação Física teve sua garantia ameaçada em todos os níveis da Educação Básica em 2016, quando foi proposta a Medida Provisória (MP) n. ${ }^{\circ} 746$ com o intuito de promover alterações na legislação educacional brasileira, mais especificamente na estrutura do ensino médio. Dentre as modificações, essa medida indicou a restrição da obrigatoriedade do ensino de Artes e Educação Física apenas à educação infantil e ao ensino fundamental, tornando-as facultativas no ensino médio.

Após manifestações e críticas provenientes de professores, estudantes, pesquisadores e movimentos sociais, a MP n. 746 foi modificada e, em 2017, foi convertida na lei n. ${ }^{\circ}$ 13.415/17. A nova legislação manteve a obrigatoriedade da Educação Física no ensino médio, assim como estava estabelecido nas leis anteriores (BRASIL, 2001; 2003). Porém, ao tratar da Base Nacional Comum Curricular (BNCC), a lei aponta que deverão ser incluídos estudos e práticas de Educação Física, Arte, Sociologia e Filosofia no ensino médio (BRASIL, 2017).

Nota-se que, apesar de a Educação Física não ter deixado de ser obrigatória, as mudanças na LDBEN trazem alguns riscos à área, principalmente ao apresentar termos conflitantes no texto: "componente curricular" e "estudos e práticas".

Se a Educação Física está garantida no ensino básico, por que há um destaque para o ensino médio, enfatizando a obrigatoriedade de estudos e práticas? A inclusão da expressão "estudos e práticas" abre precedentes para que os conteúdos sejam contemplados em outras disciplinas escolares, projetos extracurriculares ou grupos de treinamento esportivo, sendo 
então descaracterizada como componente curricular. A denominação "práticas" refere-se a procedimentos e atividades, retomando o passado utilitarista do movimento humano e fragmentando do conhecimento produzido. A alteração se configura como uma ameaça ao espaço da Educação Física no currículo do ensino médio e um retrocesso nas conquistas obtidas ao longo das últimas décadas.

Esse retrocesso pode ser confirmado por meio do fato de que a reforma atual levanta questões já suscitadas há mais de 15 anos em estudos sobre as mudanças ocorridas no campo educacional em 1998 (VAGO, 1999; DOMINGUES; TOSCHI; OLIVEIRA, 2000). Naquele momento, já se alertava sobre a possibilidade de usos interessados e irresponsáveis da recente LDBEN (BRASIL, 1996) com relação à Educação Física e os possíveis desdobramentos:

A perda de sua identidade como disciplina curricular - isto é, como portadora de um conhecimento a ser oferecido aos alunos - é o principal deles, do qual decorre seu alijamento das discussões que envolvem o conjunto das práticas escolares, que inviabiliza sua participação na formação dos alunos - torna-se um tempo à parte, um apêndice, ou um produto que a escola oferece aos alunos para atraí-los. A educação física continuaria figurando no currículo da escola, mas desfigurada de seu caráter de área do conhecimento (VAGO, 1999, p.40).

Vago (1999) considerou que as Diretrizes Curriculares Nacionais ${ }^{6}$ representaram um contraponto legal e uma ferramenta importante contra o problema da descaracterização da Educação Física como disciplina. Isso porque o documento a definiu como uma área de conhecimento que as escolas estavam obrigadas a contemplar. Essa questão, superada na reforma educacional de 1998, com o tratamento curricular do ensino de Educação Física, volta à tona na atualidade. Lembramos ainda que a falta de critérios para organização do ensino que fora observada anteriormente continuou a ser ignorada pela reforma do ensino médio em 2016.

As reformas educacionais têm sido caracterizadas como programas de governo e geralmente não partem de necessidades coletivas. Com isso elas não perduram mais que os mandatos e não envolvem efetivamente os professores, gerando descontinuidade nas propostas e descompromisso social com a mudança (DOMINGUES; TOSCHI; OLIVEIRA, 2000).

Essa descontinuidade está sendo percebida pela Educação Física a partir da nova lei. Há um chamado à autocrítica da área e foram retomadas algumas questões: como e quais experiências pedagógicas têm sido desenvolvidas? Qual a contribuição da Educação Física para o currículo do ensino médio?

Para pensar nessas questões, selecionamos os Institutos Federais de Educação, Ciência e Tecnologia como recorte de estudo, por desenvolverem uma proposta de Educação Básica e Profissional de forma integrada.

6 Em 1998, foram aprovadas pela Câmara de Educação Básica do Conselho Nacional de Educação e publicadas a Resolução n. ${ }^{\circ} 2$ de 7 de abril de 1998 e a Resolução n. ${ }^{\circ} 3$ de 26 de junho de 1998, que instituíram as Diretrizes Curriculares Nacionais para o ensino fundamental e para o ensino médio, respectivamente. 
Em 2008, a lei n. ${ }^{0} 11.892$ institui a Rede Federal de Educação Profissional, Científica e Tecnológica e cria 38 Institutos Federais (IFs) em todos os estados brasileiros. No artigo $2^{\circ}$, a lei define que são "instituições de educação superior, básica e profissional, pluricurriculares e multicampi, especializados na oferta de educação profissional e tecnológica nas diferentes modalidades de ensino" (BRASIL, 2008). O principal objetivo dos IFs é ministrar o ensino técnico integrado ao ensino médio, havendo a obrigatoriedade de oferta de um mínimo de $50 \%$ das vagas destinadas a essa ação. Outros objetivos abrangem a oferta da educação superior e de cursos de formação inicial e continuada, a realização de pesquisas aplicadas e o desenvolvimento de atividades de extensão.

Os cursos técnicos integrados são uma modalidade de ensino onde se articulam, de forma simultânea, a educação profissional técnica e o ensino médio. Em função da carga horária elevada, os cursos são organizados em período integral, manhã e tarde. Sendo assim, a jornada escolar dos alunos é de aproximadamente 30 horas por semana.

Os IFs têm apontado um cenário diferenciado com um histórico de sucesso na educação brasileira. Um exemplo disso foram as médias alcançadas pelos alunos, similares a alunos de países desenvolvidos, na edição de 2015 do Programa Internacional de Avaliação de Estudantes (PISA). Contudo, o Ministério da Educação (MEC) vem desconsiderando o desempenho dos IFs ao ignorar os bons resultados - como as notas obtidas no Exame Nacional do Ensino Médio (ENEM) -, além de manter um discurso generalizante de fracasso do ensino médio brasileiro.

A excelência alcançada por estas instituições tem sido protagonizada principalmente pela integração e ação de servidores, alunos, comunidade e as diversas áreas do conhecimento, dentre elas a Educação Física.

Atualmente, passamos por um momento crítico, em que a legitimidade da Educação Física no ensino médio está sendo questionada. Por isso, apresentar, mesmo que de modo sucinto e pontual, as experiências exitosas de professores que atuam nos IFs, pode fornecer indicativos de qual caminho a Educação Física pode trilhar para se consolidar no novo currículo do ensino médio. Nesse contexto, o objetivo deste trabalho foi identificar e analisar elementos que contribuem para a consolidação da Educação Física no ensino médio integrado ao ensino técnico em IFs, a partir de diários de aulas e registros de atividades de professores.

\section{MÉTODO}

Do ponto de vista metodológico, a pesquisa se caracterizou como do tipo descritiva, de abordagem qualitativa e com enfoque em narrativas autobiográficas.

A narrativa autobiográfica inspira-se sempre, ao menos em parte, na preocupação de atribuir sentido, de encontrar a razão, de descobrir uma lógica ao mesmo tempo retrospectiva e prospectiva, uma consistência e uma constância, de estabelecer relações inteligíveis, como a do efeito com a causa eficiente, entre estados sucessivos, constituídos como etapas de um desenvolvimento necessário (BOURDIEU, 2005, p.75). 
Numa perspectiva autobiográfica, o instrumento de pesquisa empregado foi o diário de aula elaborado por professores. Para melhor compreensão do contexto de elaboração da investigação são necessárias algumas considerações.

Três pesquisadores do estudo trabalham como docentes da área de Educação Física em diferentes campi de IFs nos Estados de Minas Gerais e São Paulo. Como prática reflexiva, os três docentes fizeram registros e observações das aulas, de pesquisas, dos projetos de extensão e de atividades extracurriculares coordenadas por eles. Como sugere Zabalza (2004), os diários são utilizados como instrumentos de pesquisa na área educacional, podendo ser entendidos como documentos em que os professores anotam suas impressões sobre os acontecimentos durante as aulas. Os relatos consistiram em uma autoanálise da prática pedagógica dos professores com a descrição de atividades e estratégias utilizadas, dos resultados obtidos, dos dilemas e problemas encontrados e da percepção das opiniões dos alunos.

Foram coletados os diários referentes a 2016, redigidos pelos três docentes. Todos os registros foram agrupados em um relato único que descrevia algumas atividades realizadas. Cada relato foi analisado por três pesquisadores, exceto o próprio autor. Durante essa etapa, utilizamos como referencial a análise temática proposta por Minayo (1993), que tem o objetivo de identificar temas relevantes num corpo de informações. Assim, os registros realizados pelos professores/pesquisadores foram organizados, lidos sucessivamente, interpretados e codificados para definição dos temas significativos para o problema de estudo.

\section{RESULTADOS E DISCUSSÃO}

A apresentação dos dados da pesquisa foi realizada a partir da composição de quatro unidades temáticas: I) caracterização da Educação Física nos IFs; II) perfil profissional dos docentes; III) ações pedagógicas no ensino de Educação Física, e IV) ações de extensão, pesquisa e atividades extracurriculares.

\section{I) Caracterização da Educação Física nos IFs}

A Educação Física está institucionalmente inserida nos IFs como componente curricular obrigatório dos cursos técnicos integrados ao ensino médio, em comissões de trabalho ou em setor de esportes e lazer como principal área fomentadora de atividades extracurriculares, e nas atividades de extensão e pesquisa relacionadas aos cursos ofertados.

A caracterização da disciplina de Educação Física no currículo dos cursos integrados ofertados pelas instituições selecionadas neste estudo está descrita no Quadro 1. 
Quadro 1: Caracterização da disciplina de Educação Física nos campi dos IFs

\begin{tabular}{|c|c|c|c|c|c|}
\hline \multirow[b]{2}{*}{ Campi } & \multicolumn{4}{|c|}{ Carga horária } & \multirow[b]{2}{*}{ Ementa } \\
\hline & $\begin{array}{c}1^{\circ} \\
\text { ano }\end{array}$ & $\begin{array}{c}2^{\circ} \\
\text { ano }\end{array}$ & $\begin{array}{c}3^{\circ} \\
\text { ano }\end{array}$ & Total & \\
\hline $\begin{array}{l}\text { Instituto } \\
\text { Federal } 1 \\
\text { (IF-1) }\end{array}$ & $\begin{array}{c}66 \mathrm{~h} 40 \\
\min \end{array}$ & $\begin{array}{c}33 \mathrm{~h} 20 \\
\min \end{array}$ & $\begin{array}{c}66 \mathrm{~h} 40 \\
\min \end{array}$ & $\begin{array}{c}166 \mathrm{~h} \\
40 \\
\min \end{array}$ & $\begin{array}{l}\text { Jogos, esportes, lutas, danças e ginásticas em } \\
\text { relação aos seus universos socioculturais, } \\
\text { científicos, fisiológicos, filosóficos e } \\
\text { estéticos, com objetivo de proporcionar } \\
\text { ao aluno, oportunidades de ampliação dos } \\
\text { elementos da cultura de movimento. }\end{array}$ \\
\hline $\begin{array}{l}\text { Instituto } \\
\text { Federal } 2 \\
\text { (IF-2) }\end{array}$ & $60 \mathrm{~h}$ & $60 \mathrm{~h}$ & $60 \mathrm{~h}$ & $180 \mathrm{~h}$ & $\begin{array}{l}\text { Conteúdos da cultura corporal e suas } \\
\text { relações, abrangendo os esportes, jogos, } \\
\text { ginásticas, danças e lutas; conhecimentos } \\
\text { acerca dos princípios biológicos, } \\
\text { socioculturais e políticos que norteiam as } \\
\text { práticas corporais. }\end{array}$ \\
\hline $\begin{array}{l}\text { Instituto } \\
\text { Federal } 3 \\
\text { (IF-3) }\end{array}$ & $67 \mathrm{~h}$ & $67 \mathrm{~h}$ & 0 & $134 \mathrm{~h}$ & $\begin{array}{l}\text { Introduzir a cultura de movimento aos } \\
\text { estudantes por meio de brincadeiras, jogos, } \\
\text { esportes, lutas, ginásticas, danças, práticas } \\
\text { de aptidão física e conhecimento orgânico } \\
\text { do corpo, em benefício do exercício crítico } \\
\text { e reflexivo da cidadania, da saúde e da } \\
\text { melhoria da qualidade de vida integrados à } \\
\text { dimensão sociocultural e política. }\end{array}$ \\
\hline
\end{tabular}

Fonte: Projetos políticos pedagógicos dos cursos dos IFs em que os professores atuam 2016.

Por meio das ementas apresentadas, notamos que a concepção de Educação Física adotada pelos IFs procura superar o ensino tecnicista e esportivista da área, buscando a contextualização e diversificação de conteúdos que possibilitem a apropriação crítica e autônoma das diversas manifestações de cultura de movimento. Essas questões corroboram as ideias de Bracht e González (2005, p.155), ao apontarem que o objetivo da Educação Física escolar é "formar indivíduos dotados de capacidade crítica em condições de agir autonomamente na esfera da cultura corporal de movimento e de forma transformadora como cidadãos políticos".

Vale ressaltar que os esportes, jogos, lutas, danças, ginásticas e exercícios físicos estão constantemente em diálogo na sociedade, ora objetificados em produtos de consumo, ora como informações na mídia ou em sua relação com a saúde e, por esse motivo, tais manifestações devem ser tratadas criticamente em momento e lugar adequados. É nesse sentido que os IFs do presente estudo entendem a Educação Física escolar como tempo e espaço para alargar possibilidades de movimento, de sentidos e significados nas diversas manifestações da cultura de movimento. Em outros termos, a Educação Física visa construir 
uma autonomia crítica, possibilitando ao aluno a vivência de novas experiências, a mobilização de seus desejos e potencialidades, e a consciência de suas vinculações socioculturais.

No caso do ensino médio, os jovens possuem especificidades em relação a sua forma de se manifestar, dialogar, organizar e interagir com o mundo ao seu redor que não podem ser ignoradas. Se os professores e as instituições de ensino não consideram essas singularidades e diversidades e não compreendem os anseios e expectativas dos alunos, haverá uma incomunicabilidade entre os sujeitos escolares (LIMA; LIMA, 2012).

A Educação Física, através da ação-reflexão, problematizando as práticas da cultura corporal de movimento presentes nas culturas juvenis, pode colaborar para que os jovens-alunos do Ensino Médio tornem-se mais satisfeitos, integrados, conscientes, e sintam-se mais confiantes e seguros em relação ao seu destino e ao das outras pessoas, desencadeando assim uma atuação social mais efetiva (LIMA; LIMA, 2012, p. 228).

Para isso, é necessário ter uma proposta pedagógica condizente com os reais objetivos da Educação Física para o ensino médio. Portanto, diversificar os conteúdos, promover o diálogo, valorizar os conhecimentos trazidos pelos jovens, comprometer-se com a disciplina, cumprir a ementa do curso, observar as necessidades e os interesses dos alunos, levam a uma aprendizagem significativa e bem-sucedida. Oliveira (2004) pondera que a adequada organização dos conteúdos é longa e trabalhosa, porém de extrema necessidade para alcançar a legitimação da Educação Física no sistema educacional.

Em relação à distribuição da carga horária, o total nas três instituições varia entre 134 e 180 horas, sendo que no IF-1 e IF-2 essa carga horária é distribuída nos três anos do ensino médio, enquanto no IF-3 as aulas se concentram apenas no primeiro e segundo anos.

O fato do IF-3 não ministrar aulas da disciplina no terceiro ano configura um dos problemas que a área enfrenta em função da falta de definição de critérios para o ensino na lei. Não raramente, algumas escolas optam por reduzir ou excluir os conteúdos de Educação Física no último ano do ensino médio com o objetivo de disponibilizar mais tempo para a preparação dos alunos para os vestibulares. Considerando que esses conteúdos são também avaliados pelo ENEM, podemos inferir que há uma hierarquização e priorização de conhecimentos a serem ofertados em algumas instituições.

No âmbito dos IFs, consideramos um aspecto importante: a autonomia dos docentes para elaborar e propor a organização curricular de conteúdos e ementas, gerando um compromisso pedagógico e uma melhor adequação à realidade local.

\section{II) Perfil profissional dos docentes}

Os professores dos IFs participantes desta investigação possuem a titulação de mestre, com média de 8 anos de formação e 2,5 anos de atuação na Rede Federal de Educação Profissional, Científica e Tecnológica. 
Um elemento que favorece a qualificação das práticas pedagógicas da Educação Física nos IFs se refere ao perfil dos docentes. Os três professores possuem suas trajetórias de formação acadêmica em universidades públicas: (i) IF-1, licenciatura e bacharelado em Educação Física e mestrado em Educação; (ii) IF-2, licenciatura e bacharelado em Educação Física e mestrado na área de Educação Física; e (iii) IF-3, licenciatura plena em Educação Física e mestrado na área da Educação Física. Ademais, todos os professores frequentam grupo de estudos vinculado a uma universidade, sendo que um deles está cursando o doutorado e os demais também pretendem obter nova titulação.

O envolvimento com a pós-graduação strictu sensu demonstra maior capacitação profissional no exercício da docência em comparação a outros contextos. A atualização de conhecimentos por meio da pesquisa tende a valorizar a Educação Física como uma profissão dotada de saberes específicos que dispõe de mão de obra altamente qualificada, em detrimento de uma atuação artesanal, descomprometida e meramente ocupacional (LAWSON, 1984).

A média de 8 anos de formação citada representa um período importante para o desenvolvimento e amadurecimento profissional, nos termos de Tardiff (2002), de saberes experienciais, isto é, de saberes construídos e oriundos do exercício da profissão. No entanto, podemos inferir que os saberes da experiência não se esgotam apenas na atuação docente, induzindo um esvaziamento da dimensão cognitiva do ensino e na criação de teorias particulares norteadoras. No atual estudo, os docentes permanecem se qualificando e em diálogo constante com a universidade.

Outro elemento que contribui para a intervenção docente são as condições de trabalho. Vale ressaltar que a Rede Federal de Educação Profissional, Científica e Tecnológica possibilita uma realidade de prática docente que, normalmente, não é verificada nas escolas públicas municipais e estaduais.

Os professores dos campi analisados possuem um regime de trabalho de dedicação exclusiva com uma carga horária média de aulas de 10,5 horas por semana. Segundo estudo comparativo entre instituições federais e estaduais realizado por Pereira e Silva (2004), a carga horária média de trabalho dos professores de Educação Física da rede federal é $37,8 \%$ menor em relação à dos professores da rede estadual.

Tal combinação de distribuição da carga horária de trabalho somada à qualificação dos docentes e ao regime de dedicação exclusiva permitem o desenvolvimento da tríade ensino-pesquisa-extensão e o exercício de outras atividades complexas, como a de representação, atuação em comissões, de gestão e de formação continuada.

No âmbito do ensino, isso permite maior qualidade no planejamento de aulas, reflexão como prática tácita e autônoma, maior envolvimento com questões críticas na sociedade, o que elevam as relações de sentido entre Educação Física e mundo. O acúmulo de trabalho e empregos dos docentes representa um problema recorrente no país, pois interfere negativamente na elaboração do planejamento, pois quanto mais funções são concentradas por eles, menor é o tempo disponível para a organização pedagógica (JARDIM et al., 2014). 
Na extensão, os professores têm a possibilidade de desenvolver projetos com captação de bolsas discentes, verba para compra de material de consumo e/ou permanente e bolsa docente nos mais variados temas: desporto, saúde, cultura, educação, meio ambiente, comunicação, direitos humanos e justiça, trabalho, tecnologia e produção.

Os IFs permitem e incentivam os professores ao desenvolvimento de pesquisas. Nessa perspectiva, Stenhouse (1993) sugere que o professor seja pesquisador de sua própria prática. Para o autor, esse poderia ser um caminho de rompimento da dicotomia entre teoria e prática.

Dessa forma, os IFs apresentam um diferencial em relação às demais instituições de ensino, possuindo um regime de trabalho de 40 horas/semanais com dedicação exclusiva, oferecendo aos professores tempo adequado para planejamento de aulas e desenvolvimento de outras atividades.

\section{III) Ações Pedagógicas no Ensino de Educação Física}

As experiências do IF-1, IF-2 e IF-3 apresentam, de forma similar, a mediação e a organização docente como determinantes para a legitimação da Educação Física enquanto disciplina. Observamos que, nos registros, os docentes investigam as experiências dos alunos sobre a Educação Física no ensino fundamental. Assim, por meio de avaliações diagnósticas, os professores partem do que os alunos já conhecem, buscando diversificar e ampliar os conteúdos de ensino, considerando a coparticipação dos alunos na elaboração do plano de ensino. Essa metodologia torna efetiva a participação nas aulas de Educação Física e, quando existem casos de limitação de saúde que impossibilitam a prática, os alunos se envolvem em outras atividades, como filmagens de aula, redação de um relatório e auxílio na organização de atividades.

Dessa forma, a disciplina possui uma organização didática que parte de uma apresentação panorâmica dos conteúdos, objetivos, metodologia e avaliação. Os professores afirmam que muitos alunos relataram um estranhamento a estas questões, já que, em experiências anteriores, a Educação Física não era dotada de uma sistematização pedagógica.

O planejamento das aulas é pautado na diversificação dos conteúdos e na criação de situações de aprendizagem que promovam a participação de todos os alunos. Isso implica ao docente conhecer os fatores que favorecem e desfavorecem a mobilização pelas aulas de Educação Física, como: (i) ter maior atenção com a participação feminina (SOUSA; ALTMANN, 1999; SOUZA JÚNIOR; DARIDO, 2003); (ii) abordar elementos conceituais a partir de experiências corporais; (iii) não abandonar a diretividade nas aulas (OLIVEIRA, 2010); evitando-se a vigilância de um aluno sobre o outro em relação ao nível de habilidade, questões de gênero e sexualidade (ALTMANN, 1998); (iv) ampliar as manifestações de cultura de movimento (BETTI et al., 2015); e (v) tomar os saberes dos alunos como ponto de partida (CHARLOT, 2000; FREIRE, 2006).

As ações citadas impedem o descompromisso com a qualidade de ensino ou práticas "vazias". Caso contrário, se a pretensão do professor de Educação Física for apenas ocupar o tempo da aula de seus alunos com qualquer atividade: 


\begin{abstract}
De forma incipiente, pode-se caracterizar esta não aula quando: no tempo-espaço designado/reservado para que a prática pedagógica do professor ocorra, este não intervém de forma objetiva-intencional, privando os alunos da possibilidade de acesso à aprendizagem de um conteúdo específico e/ou do desenvolvimento de uma determinada habilidade. Geralmente este espaço pode confundir-se, ainda, com outros momentos nos quais os alunos simplesmente se divertem (recreio ou aula vaga), sem que haja qualquer diretividade do professor com intenções pedagógicas de aprendizagem (MACHADO et al., 2010, p.133).
\end{abstract}

Descrevemos, a seguir, algumas experiências que exemplificam a atuação docente nos campi:

Experiência IF-1: Foi abordado com as três turmas de terceiro ano o conteúdo jogo virtual e experiência corporal educativa. A unidade foi composta por doze aulas e teve como objetivo contextualizar novas possibilidades de atualização do jogo virtual em experiência corporal. Nas seis primeiras aulas, os alunos vivenciaram alguns jogos no computador, no laboratório de informática, e posteriormente experimentaram a atualização na quadra, por meio de jogos que envolviam movimentos e regras semelhantes ao quadribol, pokemón e pac man. Nas quatro aulas seguintes foi realizada a apresentação de grupos. Cada grupo deveria criar e propor uma atividade atualizada do jogo virtual. Diversos jogos foram propostos e atualizados corporalmente: bomb jack, agar i/o, slenderman, counter strike, dead by daylight. Nas últimas duas aulas foram realizadas discussões sobre produção textual elaborada pelos alunos sobre as semelhanças e diferenças entre os jogos e a experiência corporal;

Experiência IF-2: Foram coletadas as fichas de avaliação referentes a uma unidade didática em que foi trabalhado o conteúdo das atividades circenses com alunos de quatro turmas do segundo e terceiro ano dos cursos técnicos integrados ao ensino médio. A unidade foi composta por dez aulas e teve como objetivo proporcionar experimentação do corpo por meio de acrobacias de solo em grupos. Os alunos foram estimulados a se organizarem para a preparação de uma coreografia a partir dos movimentos aprendidos em aula. A maioria dos alunos ainda não tinha experimentado as atividades circenses e demonstraram prazer e gosto pela prática. Eles reconheceram a diversificação de conteúdos e a vivência de novas práticas como os principais aspectos da metodologia de ensino adotada e se manifestaram favoráveis com a dinâmica proposta. Durante as práticas foi observado que os alunos identificaram suas dificuldades e limitações com relação ao baixo nível de flexibilidade, força muscular e equilíbrio. Eles também se conscientizaram sobre as dificuldades de se trabalhar em grupo, como a necessidade de organização, a falta de compromisso de alguns componentes, a falta de confiança no colega, as discordâncias e discussões travadas para a tomada de decisões coletivas. Apesar dos problemas encontrados, os alunos cooperaram uns com os outros em busca do objetivo proposto. Eles reconheceram a necessidade de ajudar o outro para a execução dos movimentos, auxiliando com correções, fornecendo sugestões de melhoria e garantindo a segurança pessoal. Ao experimentar as formações de figuras acrobáticas, eles também reconheceram as características e qualidades dos colegas ao definirem quais as pessoas poderiam desempenhar a função de base ou volante. Eles 
adaptaram os movimentos conforme as necessidades de cada componente e fizeram as alterações necessárias. Os alunos reconheceram que as acrobacias favoreceram a aproximação com pessoas da turma que eles tinham pouco contato. Foram capazes de identificar alguns benefícios proporcionados pelas aulas e compreenderam os efeitos da atividade sobre o organismo. Dentre eles podemos citar o desenvolvimento de habilidades, a integração entre os colegas, a diversão, a experimentação do corpo, a superação de desafios e a melhoria do condicionamento físico e da saúde. Em geral, os alunos perceberam que suas maiores dificuldades no início da prática - as capacidades físicas e as competências relacionadas ao trabalho de equipe - foram as mais desenvolvidas ao longo das aulas, percebendo a importância do conteúdo para o convívio social e para a vida. Os alunos consideraram a atividade como integradora e parece que esse fator se configura como uma necessidade e/ou interesse deles; e

Experiência IF-3: A unidade didática sobre atividades paralímpicas "goalball, futebol de cinco e vôlei" foi composta por doze aulas. Ao final da sequência pedagógica os alunos perceberam que as atividades foram muito enriquecedoras, pois despertaram a sensibilidade de olhar para as dificuldades que as pessoas com deficiências enfrentam cotidianamente ao superar as próprias limitações, demonstrando que são capazes de realizar muitas atividades, inclusive esportivas. Outras sensações também foram percebidas, como a importância da audição, a ausência e/ou a presença da luz solar, a falta de equilíbrio e a dificuldade de se localizar e de se movimentar no espaço. Essas atividades foram significativas em relação à dimensão da inclusão, adaptação e diversificação dos conteúdos esportivos, possibilitando aos alunos o desenvolvimento da empatia por pessoas que possuem deficiências visuais e físicas. Outra experiência apresentou quais objetivos pedagógicos da Educação Física são valorizados pelos discentes ao longo da execução de um plano de ensino, sendo analisada por meio de fichas de avaliação no início e no final do ano letivo. No primeiro contato com as aulas de Educação Física, os alunos apresentaram uma visão de que a disciplina contribui para conhecer e praticar esportes, jogos e brincadeiras, desenvolver habilidades motoras e capacidades físicas, bem como para a melhoria da saúde e qualidade de vida. Ao longo de um ano de aulas, a maioria dos discentes passou a valorizar a Educação Física como promotora da socialização, da formação de valores e do pensamento crítico. Isso denota o entendimento dos alunos referente à importância que a Educação Física tem na formação humana e de cidadania, principalmente em relação à percepção da integração e da socialização por meio de situações em que eles têm diferentes possibilidades de pensar, agir e refletir de forma crítica sobre o quê e por que fazem determinadas atividades, além de colaborar de forma significativa para a formação de valores humanos, como o respeito, a tolerância, a cooperação e a amizade. Um número maior de alunos percebeu a importância da disciplina para a educação em saúde e não deixaram de reconhecer o ensino e prática de esportes como um dos objetivos principais. A categoria de saúde foi vista como utilitarista pelos alunos ao apontarem de forma generalizada que a prática da atividade física serve como meio de manter ou obter saúde. Esse fato reflete a necessidade de conscientizar os estudantes sobre os conceitos de "para que, como e por que" promover a saúde. Em contrapartida, os aspectos relacionados ao lazer tiveram pouco destaque, o 
que implica na falta de abstração dos alunos em relacionar os elementos lúdicos durante as atividades realizadas.

Na perspectiva dos professores, as experiências relatadas permitiram destacar que:

IF-1: "Diversos alunos tiveram intensa mobilização provocada pelo tema, bem como enalteceram a própria participação protagonista e criativa nas aulas".

IF-2: “O espaço da prática como importante facilitador para a sociabilidade, o relacionamento com o outro, o trabalho em equipe, aprendizagem afetiva e emocional, o autoconhecimento, o desenvolvimento de habilidades, a melhoria da aptidão física e o lazer ativo".

IF-3: "As aulas possibilitaram o protagonismo e a autonomia dos alunos durante o processo de ensino e aprendizagem, atingindo satisfatoriamente os objetivos educacionais e inclusivos proporcionados pela prática de atividades paralímpicas" e que ao término do ano letivo "os alunos aumentaram a compreensão sobre a cultura de movimento relacionada aos diversos conteúdos abordados".

As experiências sobre as atividades apresentadas, ao serem pedagogicamente sistematizadas como meio e conteúdo de ensino, contribuíram de forma significativa para a formação e o desenvolvimento humano dos alunos e se aproximaram da teoria de Cagigal (1979) e de outros estudos com objetivos semelhantes (BETTI, 1991; FREIRE, 1996; BARBIERE, 2001).

Nessa direção, os dados indicam que os alunos valorizam e percebem a relevância da Educação Física na medida em que vão se apropriando do conhecimento sistematizado ensinado ao longo do ano letivo. Resultados similares foram encontrados em uma pesquisa com alunos de ensino médio e gestoras de uma escola que deixaram de compreender a Educação Física como uma prática pela prática e passaram a reconhecê-la como componente curricular quando conheceram uma nova proposta de organização e planejamento orientado por princípios didáticos, como a problematização e a contextualização dos temas estudados com a realidade dos adolescentes (KRAVCHYCHYN; OLIVEIRA; CARDOSO, 2008). A nova experiência possibilitou a compreensão das características formativas da disciplina e da existência de um corpo de conhecimentos sistematizados a ser oferecido, contribuindo para a reconstrução do conceito a respeito da Educação Física por parte dos alunos.

Portanto, no ensino médio, a Educação Física necessita estabelecer outros objetivos além do ensino de esportes, pois existe uma diversidade de conteúdos significativos para a realidade e expectativa dos alunos. Quando as atividades propostas atendem os interesses dos jovens, elas promovem aprendizagens mais efetivas e despertam a consciência crítica, favorecendo o pensamento e o debate (LIMA; LIMA, 2012).

Nesse sentido, as experiências dos IFs apresentados neste estudo indicam que quando há a diversificação de conteúdos, quando os docentes consideram a coparticipação dos alunos, buscam criar desafios e promovem situações de aprendizagens significativas, os alunos reconhecem a importância da Educação Física escolar e participam das aulas de forma efetiva. 


\section{IV) Ações de extensão, pesquisa e atividades extracurriculares desenvolvidas nos campi}

Nos IFs as ações desenvolvidas pela Educação Física extrapolam o currículo mínimo e se ampliam para as atividades de extensão, de pesquisa e eventos extracurriculares.

Em uma das instituições analisadas existe uma comissão de trabalho e nas demais um Setor de Esportes e Lazer, todos designados para as atribuições de planejar, organizar, coordenar e avaliar o calendário de atividades relacionadas à Educação Física, como de treinamento esportivo, de participação em competições, de pesquisa e extensão voltadas para a atividade física, saúde, lazer e o esporte.

Dentre as principais ações desenvolvidas, podemos elencar a participação nos Jogos dos IFs - competição esportiva organizada pelas instituições da rede federal, nas etapas local, regional e nacional; a realização de jogos esportivos de integração - eventos e competições interclasses voltados para a socialização entre alunos; a realização de eventos comemorativos sobre esporte, cultura, saúde e lazer ao longo do ano letivo; e a organização de gincanas e festivais artísticos e culturais. Essas ações enriquecem a formação dos alunos, contribuindo para contextualização social, econômica e histórico-política, bem como para o desenvolvimento do pensamento crítico e reflexivo.

Além dos eventos, as atividades esportivas e culturais são desenvolvidas por meio de projetos de extensão, de forma contínua e sistematizada. É importante ressaltar que a implantação dos projetos é viabilizada pela estrutura da Rede Federal de Educação Profissional, Científica e Tecnológica, que prioriza uma educação baseada na tríade de ensino, pesquisa e extensão, e destina parte de seu orçamento para editais de fomento para projetos de extensão e pesquisa, sendo possível a captação de recursos para bolsas de iniciação extensionista e/ou científica, para materiais e equipamentos. A realização dos projetos depende do envolvimento e iniciativa do docente, tendo ele a liberdade de fazer ou não uma proposta.

Nos três IFs estudados, existem projetos idealizados e coordenados pelos professores de Educação Física, proporcionando uma variedade de atividades para a comunidade escolar e externa. Gariglio (2002) observou que existe uma especificidade na rede federal, pois a carga horária de aulas distribuída em dois turnos faz com que os alunos tenham as expectativas aumentadas quanto às possibilidades de práticas corporais na própria escola nos momentos de descanso e lazer que passam a ser vividos lá dentro. A área acaba acoIhendo essa necessidade dos alunos e recebendo certo prestígio deles. Para exemplificar, no IF-1, os alunos contam com vivência de esportes coletivos com bola (futsal, basquete, handebol e voleibol) e de jiu-jitsu. No IF-2, as ações propiciam a vivência de esportes (futsal, handebol, atletismo, basquete, peteca, tênis de mesa e judô), dança e artes circenses. No IF-3 é ofertado o projeto de modalidades esportivas coletivas com ênfase no lazer.

A Educação Física se configura como área de grande potencial extensionista e tem desempenhado um importante papel no acolhimento da comunidade externa. Os projetos de extensão desenvolvidos são importantes para aproximar a comunidade local dos conhecimentos da cultura de movimento, contribuindo para a formação integral dos alunos que têm a possibilidade de participar enquanto público, assim como bolsistas/ monitores das atividades. 
Outra forma de contribuição da Educação Física para a formação dos alunos dos IFs se situa no cenário da pesquisa. Alunos do ensino médio têm a oportunidade de fazer uma iniciação científica em estudos nas temáticas de saúde, qualidade de vida e lazer, além de terem oportunidades de participação em eventos científicos e desenvolverem habilidades de elaboração e apresentação de trabalhos.

Nota-se que o trabalho desenvolvido nos IFs vai além do currículo mínimo abordado pela área de Educação Física em outras instituições de ensino. O ensino é articulado com os projetos de extensão, atividades extracurriculares e pesquisa. Portanto, o trabalho do professor de Educação Física é mediado por outras atividades que complementam os conteúdos ministrados nas aulas regulares.

As experiências proporcionadas nos IFs, por trazerem uma visão diferenciada das aulas de Educação Física, podem ser consideradas uma experiência bem-sucedida na área e, como acredita Maciel (2013), acabam refletindo de alguma forma nas demais esferas educacionais (estadual e municipal), sejam públicas ou privadas.

\section{CONCLUSÕES}

As características dos IFs, como a valorização docente (remuneração e plano de carreira), a dedicação exclusiva do professor à instituição e a carga horária de aulas compatível com o tempo de planejamento e desenvolvimento de pesquisas e projetos de extensão constituem fatores que favorecem as ações didático-pedagógicas e a conquista de prestígio da Educação Física como componente curricular no ensino médio. Porém, esse cenário não é observado na maioria das escolas públicas do mesmo nível.

Os dados deste estudo reforçam a ideia de que o caminho para a legitimação da Educação Física na escola passa principalmente pelo trabalho docente de planejamento adequado e orientado por princípios didáticos e metodológicos, como a sistematização de um corpo de conhecimentos a ser ofertado. O professor pode aderir, contestar, resistir ou criar alternativas para os modelos curriculares impostos, já que o espaço da prática docente é um campo aberto de possibilidades de intervenção que deve ser potencializado (VAGO, 1999).

Dentre os fatos consensuais que justificam a defesa da Educação Física no ensino médio, destacamos que ela contribui com ações pedagógicas planejadas para a formação integral e crítica dos alunos, por meio do desenvolvimento de conteúdos da cultura de movimento que propiciam o exercício da autonomia, da criatividade, da expressão, do trabalho em equipe, do bom convívio social, da ética, da cidadania, do respeito às diferenças e da resolução de problemas.

O momento político atual e os novos dispositivos legais têm vinculado a educação apenas ao mercado de trabalho, ao considerar em primeiro plano o individualismo, o lucro e a competição. Assim, a tendência da (contra)reforma do ensino médio é conduzir à fragmentação do conhecimento, ao déficit da formação educacional nas diferentes áreas 
de conhecimento, a imediata formação para o trabalho de nível técnico e ao abismo entre o ensino médio e o superior.

Ao contrário de como vem sendo entendida, corroboramos Mészáros (2005), ao considerar a educação como criação e transformação do ser humano, tendo em vista a superação da lógica desumanizadora que ameaça a sociedade.

\section{REFERÊNCIAS}

ALTMANN, Helena. Rompendo fronteiras de gênero: Marias (e) homens na educação física. 1998. 108 f. Dissertação (Mestrado em Educação) - Universidade Federal de Minas Gerais, Belo Horizonte, 1998.

BARBIERE, César A. S. Esporte educacional: uma possibilidade de restauração do humano no homem. Canoa: ULBRA, 2001.

BETTI, Mauro; MAFFEI, Willer S.; SO, Marcos R.; USHINOHAMA, Tatiana Z. Os saberes da Educação Física na perspectiva dos alunos do ensino fundamental: o que aprendem e o que gostariam de aprender. Revista Brasileira de Educação Física Escolar, São Paulo, v. 1, p. 155- 165, 2015.

BETTI, Mauro. Educação Física e sociedade. São Paulo: Editora Movimento, 1991.

BOURDIEU, Pierre. Razões práticas: sobre a teoria da ação. 6 ed. Campinas: Papirus, 2005.

BRACHT, Valter; GONZÁLEZ, Fernando J. Educação física escolar. In: GONZÁLEZ, Fernando J.; FENSTERSEIFER, Paulo E. (Orgs.). Dicionário crítico de Educação Física. ljuí: Unijuí, 2005. p. 150-157.

BRACHT, Valter; ALMEIDA, Felipe Q. A política de esporte escolar no Brasil: a pseudovalorização da educação física. Revista brasileira de ciências do esporte, v. 24, n. 3, p. 87-101, 2003.

BRASIL. Presidência da República. Lei no $\mathbf{1 3 . 4 1 5}$ de 16 de fevereiro de 2017. Altera as Leis nos 9.394, de 20 de dezembro de 1996, que estabelece as diretrizes e bases da educação nacional, e 11.494, de 20 de junho 2007, que regulamenta o Fundo de Manutenção e Desenvolvimento da Educação Básica e de Valorização dos Profissionais da Educação, a Consolidação das Leis do Trabalho - CLT, aprovada pelo Decreto-Lei no 5.452, de $1^{\circ}$ de maio de 1943, e o Decreto-Lei no 236, de 28 de fevereiro de 1967; revoga a Lei $n^{\circ} 11.161$, de 5 de agosto de 2005; e institui a Política de Fomento à Implementação de Escolas de Ensino Médio em Tempo Integral. Brasília/DF, 2017.

BRASIL. Presidência da República. Medida Provisória nº 746 de 22 de setembro de 2016. Brasília/DF, 2016.

BRASIL. Presidência da República. Lei $\mathbf{n}^{\mathbf{0}} \mathbf{1 1 . 8 9 2}$ de 29 de dezembro de 2008. Institui a Rede Federal de Educação Profissional, Científica e Tecnológica, cria os Institutos Federais de Educação, Ciência e Tecnologia, e dá outras providências. Brasília/DF, 2008.

BRASIL. Presidência da República. Lei $\mathbf{n}^{\circ} \mathbf{1 0 . 7 9 3}$ de $\mathbf{1}^{\mathbf{0}}$ de dezembro de 2003. Altera a redação do art.26, § $3^{\circ}$, e do art. 92 da Lei $n^{\circ}$ 9.394, de 20 de dezembro de 1996, que "estabelece as diretrizes e bases da educação nacional", e dá outras providências. Brasília/DF, 2003. 
BRASIL. Presidência da República. Lei no 10.328 de 12 de dezembro de 2001. Introduz a palavra "obrigatório" após a expressão "curricular", constante do § $3^{\circ}$ do art. 26 da Lei $n^{\circ}$ 9.394, de 20 de dezembro de 1996, que estabelece as diretrizes e bases da educação nacional. Brasília/DF, 2001.

BRASIL. Presidência da República. Lei no 9.394 de 20 de dezembro de 1996. Estabelece as Diretrizes e Bases da Educação Nacional. Brasília/DF, 1996.

BRASIL. Presidência da República. Lei $\mathbf{n}^{\circ} \mathbf{4 . 0 2 4}$ de 20 de dezembro de 1961. Fixa as Diretrizes e Bases da Educação Nacional. Brasília/DF, 1961.

CHARLOT, Bernard. Da relação com o saber: elementos para uma teoria. Porto Alegre: Artmed, 2000.

CAGIGAL, José M. Cultura intelectual e cultura Física. Buenos Aires: Kapelusz, 1979.

DOMINGUES, José L.; TOSCHI, Nirza S.; OLIVEIRA, João F. A reforma do Ensino Médio: A nova formulação curricular e a realidade da escola pública. Educação \& Sociedade, ano XXI, n. 70, p.63-79, 2000.

FREIRE, Paulo. Pedagogia da autonomia: saberes necessários à prática educativa. $33^{\mathrm{a}} \mathrm{ed}$. São Paulo: Paz e Terra, 2006.

FREIRE, João B. Esporte educacional. In: BARBIERI, C.; OLIVEIRA, P. C.; MORAIS, R. M. (Orgs). Esporte Educacional: uma proposta renovada. Recife: Universidade de Pernambuco/UPE-ESEF/MEE/INDESP, 1996, p. 76-83.

GARIGLIO, José A. A Educação Física no currículo de uma escola profissionalizante: um caso sui generis. Revista Brasileira de Ciências do Esporte, Campinas, v. 23, n. 2, p. 69-88, jan. 2002.

JARDIM, Nayara F. P.; PIZANI, Juliana; TEIXEIRA, Fabiane C.; BARBOSA-RINALDI, leda P. O mundo do trabalho como elemento articulador dos conteúdos da educação física escolar. Motrivivência, v. 26, n. 43, p. 150-163, 2014.

KRAVCHYCHYN, Claudio; OLIVEIRA, Amauri Ap. B.; CARDOSO, Sônia M. V. Implantação de uma Proposta de Sistematização e Desenvolvimento da Educação Física do Ensino Médio. Movimento, Porto Alegre, v. 14, n. 2, p. 39-62, 2008.

LAWSON, Hal A. Invitation to physical education. Champaign: Human Kinetics Book, 1984.

LIMA, Marcia R. C. de; LIMA, José M. de. As culturas juvenis e a cultura corporal de movimento: em busca de interlocução. Revista Teias, v. 13, n. 27, p. 219-241, 2012.

MACHADO, Thiago S.; BRACHT, Valter, FARIA, Bruno A.; MORAES, Claudia; ALMEIDA, Ueberson, ALMEIDA, Felipe Q. As práticas de desinvestimento pedagógico na Educação Física escolar. Movimento, v. 16, n. 2, p. 129-147, 2010.

MACIEL, Thiago B. A Educação Física e os esportes nos Institutos Federais em Educação, Ciência e Tecnologia: debatendo os rumos da formação dos estudantes. 2013. 179f. Dissertação (Mestrado em Políticas Públicas e Formação Humana), Universidade do Estado do Rio de Janeiro, Rio de Janeiro, 2013.

MÉSZÁROS, István. A educação para além do capital. Tradução Isa Tavares. São Paulo: Boitempo, 2005.

MINAYO, Maria C. S. O desafio do conhecimento: pesquisa qualitativa em saúde. São Paulo: Hucitec, 1993. 
setembro/2017

OLIVEIRA, Amauri A. B. Planejando a Educação Física Escolar. In: VIEIRA, José L. L. (Org). Educação Física e Esportes: estudos e proposições. Maringá: EDUEM, 2004. p. 25-55.

OLIVEIRA, Rogério C. Na "periferia" da quadra: Educação Física, cultura e sociabilidade na escola. 201f. Tese (doutorado em Educação Física). Faculdade de Educação Física, Universidade Estadual de Campinas, Campinas, 2010.

PEREIRA, Flávio M.; SILVA, Adriane C. da. Sobre os conteúdos da educação física no ensino médio em diferentes redes educacionais do Rio Grande do Sul. Revista da Educação Física, Maringá, v. 15, n. 2, p. 67-77, 2004.

SOUSA, Eustáquia S.; ALTMANN, Helena. Meninos e meninas: expectativas corporais e implicações na educação física escolar. Cadernos CEDES, Campinas, ano 19, n. 48, p. 52-68, ago. 1999.

SOUZA JÚNIOR, Osmar M.; DARIDO, Suraya C. Influências da cultura escolar no desenvolvimento de propostas co-educativas em aulas de Educação Física. Motriz, Rio Claro, v. 9, n. 3, p. 143-151, set./dez. 2003.

STENHOUSE, Lawrence. La investigación como base de la enseñanza. 2 ed. Madri: Morata, 1993.

TARDIF, Maurice. Saberes docentes e formação profissional. Petrópolis: Vozes, 2002.

VAGO, Tarcísio M. Início e fim do século XX: Maneiras de fazer educação física na escola. Cadernos Cedes, ano XIX, n. 48, 1999.

ZABALZA, Miguel. Diários de aula: um instrumento de pesquisa e desenvolvimento profissional. Porto Alegre: Artmed, 2004.

Recebido em: abril/2017

Aprovado em: julho/2017 